\title{
Polymers Having Pendant Amino Sugar Groups: Synthesis and Bioactivity of Polymers Having Free Glucosamine and $\mathrm{N}$-Acetylglucosamine
}

\author{
Yoshiyuki KoYAMA, Akira YoshIDA, and Keisuke KuRITA \\ Department of Industrial Chemistry, Faculty of Engineering, \\ Seikei University, Musashino-shi, Tokyo 180, Japan
}

(Received December 3, 1985)

\begin{abstract}
Synthesis and some properties of polymers having pendant amino sugars are described. Radical polymerization of the $p$-vinylphenyl glycoside of 3,4,6-tri- $O$-acetyl-Dglucosamine gave the corresponding polymer with $\eta_{\mathrm{inh}} 0.38-0.75$ in high yield, which was soluble in DMAc, methanol, and pyridine. Deacetylation of the polymer by alkaline hydrolysis afforded a polymer having free glucosamine groups linked at the $\mathrm{C}-1$ position. $N$-Acetylation of the original polymer followed by selective $O$-deacetylation converted the pendant groups to $\mathrm{N}$-acetylglucosamine residues. The interaction of these polymers with wheat germ agglutinin and potato lectin was examined, and the $N$-acetylglucosamine-containing polymer was found to have a strong affinity for the lectins.
\end{abstract}

KEY WORDS $p$-Vinylphenol / D-Glucosamine / $N$-Acetylglucosamine / Sugar-Containing Polymers / Bioactivity / Lectin / Agglutination /

Many kinds of polymers having pendant sugar groups ${ }^{1-5}$ and those containing sugar residues in the main chain ${ }^{6-9}$ have been extensively studied recently, and their interesting properties arising from the characteristic structures reported. For example, some polymers forming micellar structures in water owing to their amphiphilic nature, can bind organic solutes in aqueous solutions. ${ }^{1}$ Specific interactions of such polymers were also observed with enzymes $^{10,11}$ and a lectin. ${ }^{12}$ Some chemical modifications are possible at sugar residues, and pendant sugars having an anomeric hydroxyl group can be converted into derivatives such as phenylhydrazones, ${ }^{5}$ glyconic acid, ${ }^{1}$ and others.

However, no attempt has been made to prepare polymers containing pendant amino sugars linked to polymers with groups other than the amino groups to preserve the interesting properties characteristic of amino sugars. Such polymers may possibly be derived from mono- mers prepared by glycosidation of amino sugars with vinyl compounds.

We report in this paper the glycosidation of a D-glucosamine derivative, 3,4,6-tri- $O$-acetylD-glucosamine with $p$-vinylphenol and polymerization of the resulting monomer to give the corresponding polymer, which was further transformed into polymers with free glucosamine and $\mathrm{N}$-acetylglucosamine residues by chemical modifications. The interaction of these polymers with wheat germ agglutinin and potato lectin is also discussed.

\section{EXPERIMENTAL}

3,4,6-Tri-O-acetyl-2-amino-2-deoxy- $\alpha$-D-glucosyl Bromide Hydrobromide (I)

The synthetic procedure developed by Gross $^{13}$ was slightly modified. 2-Benzyloxycarbonylamino-2-deoxy-D-glucose ${ }^{14} \quad(12.0 \mathrm{~g})$ was dissolved in a mixture of $100 \mathrm{~g}$ of a $30 \%$ $\mathrm{HBr}$ solution in acetic acid and $32 \mathrm{~g}$ of acetic 


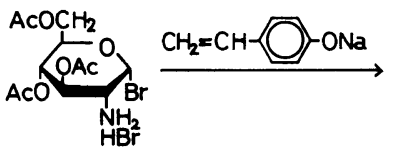

(I)

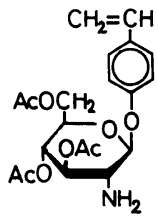

(II)

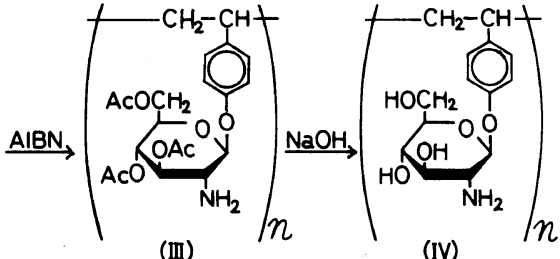

(III)

(IV)

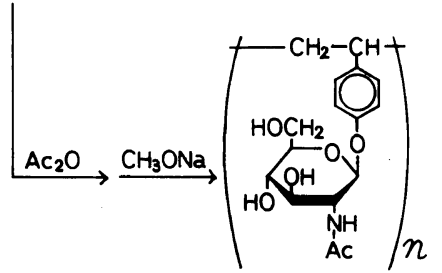

(V) anhydride at $0^{\circ} \mathrm{C}$. The temperature was kept at $0^{\circ} \mathrm{C}$ for $30 \mathrm{~min}$ and then at $15^{\circ} \mathrm{C}$ for $6.5 \mathrm{~h}$ with mechanical stirring. Ether $(100 \mathrm{ml})$ was then added to the mixture, and the mixture was left standing for $10 \mathrm{~h}$ at $5^{\circ} \mathrm{C}$. Deposited white crystals (I) were collected on a filter and washed thoroughly with ether. Yield, $13.3 \mathrm{~g}$ $(78.8 \%)$. The crystals obtained were used in the next step without further purification.

p-Vinylphenyl 3,4,6-Tri-O-acetyl-2-amino-2-deoxy- $\beta$-D-glucoside (II)

Sodium $(1.23 \mathrm{~g})$ was dissolved in dry methanol $(45 \mathrm{ml})$, and the solution was added to $16.0 \mathrm{~g}$ of $p$-vinylphenol dissolved in toluene as a $20 \%$ solution. A suspension of $12.0 \mathrm{~g}$ of $\mathbf{I}$ in $100 \mathrm{ml}$ of dry acetone was added to the solution, and the mixture was stirred at room temperature overnight. Precipitated $\mathrm{NaBr}$ was filtered and the filtrate was concentrated to about $100 \mathrm{ml}$ below $20^{\circ} \mathrm{C}$ under reduced pressure. Toluene $(200 \mathrm{ml})$ was added to the solution, and the additionally precipitated $\mathrm{NaBr}$ was removed by filtration. The filtrate was washed three times with dilute aqueous $\mathrm{NaOH}$ and once with water. After drying over $\mathrm{Na}_{2}-\mathrm{SO}_{4}$, the solution was evaporated to a solid, which was recrystallized from ethanol to give II as colorless thin plates. Yield, $1.81 \mathrm{~g}$ $(16.6 \%)$. From the mother liquor, an additional $0.52 \mathrm{~g}$ of the plates was obtained: ${ }^{1} \mathrm{H}$ NMR
$\left(\mathrm{CDCl}_{3}\right) \delta 7.35$ and 6.99 (two d, $J=8.8 \mathrm{~Hz}$, $4 \mathrm{H}$, aromatic $-\mathrm{CH}=), 6.67(\mathrm{dd}, J=11$ and $18 \mathrm{~Hz}, 1 \mathrm{H}$, vinyl $-\mathrm{CH}=), 5.64(\mathrm{~d}, J=18 \mathrm{~Hz}$, $1 \mathrm{H}$, vinyl $\left.\mathrm{CH}_{2}=\right), 5.18(\mathrm{~d}, J=11 \mathrm{~Hz}, 1 \mathrm{H}$, vinyl $\mathrm{CH}_{2}=$ ), 5.08-3.22 (m, 7H, $\beta$-pyranose), 2.11, 2.08, and 2.05 (three s, $9 \mathrm{H}$, acetyl $\mathrm{CH}_{3}-$ ), and 1.66 (broad s, 2H, $-\mathrm{NH}_{2}$ ); IR (KBr) 3380, 1730,1600 , and $1500 \mathrm{~cm}^{-1} ;[\alpha]_{\mathrm{D}}^{25}=-29.9^{\prime}$ $\left(\mathrm{CHCl}_{3}\right.$, c 1).

Anal. Calcd for $\mathrm{C}_{20} \mathrm{H}_{25} \mathrm{NO}_{8}$ (407.3): C, $58.96 \%$; H, $6.18 \%$; N, 3.44\%. Found: C, $58.96 \%$; H, 6.19\%; N, 3.44\%.

\section{Polymerization}

Monomer II (1.0 mmol) and a given amount of azobisisobutyronitrile (AIBN) were charged in a glass tube and dried under vacuum overnight. Na-dried benzene $(1.5 \mathrm{ml})$ was then transferred into the tube by vacuum distillation. The solution was solidified with dry ice-ethanol and degassed three times. The tube was sealed under vacuum and put in a thermostat at $60^{\circ} \mathrm{C}$. After $24 \mathrm{~h}$, the viscous solution was diluted with methanol and poured into ether. The precipitated white powdery polymer (III) was collected on a glass filter, washed thoroughly with ether, and dried in vacuo.

${ }^{1} \mathrm{H}$ NMR (DMSO- $\left.d_{6}\right) \delta 7.7-6.0$ (broad m, $4 \mathrm{H}$, aromatic $-\mathrm{CH}=), 5.8-2.9($ broad $\mathrm{m}, 7 \mathrm{H}$, $\beta$-pyranose), and $2.7-1.3$ (broad $\mathrm{m}, 14 \mathrm{H}$, 
$-\mathrm{CH}_{2}-\mathrm{CH}-,-\mathrm{NH}_{2}$, and acetyl $\mathrm{CH}_{3}-$ ); IR (KBr) 3400, 1740, 1600, and $1500 \mathrm{~cm}^{-1}$.

Anal. Calcd for $\left(\mathrm{C}_{20} \mathrm{H}_{25} \mathrm{NO}_{8}\right)_{n}$ : C, $58.96 \%$; $\mathrm{H}, 6.18 \%$; H, 3.44\%. Found: C, $58.12 \%$; H, $6.26 \% ; \mathrm{N}, 3.36 \%$.

\section{Deacetylation of Polymer III}

Polymer III $(50 \mathrm{mg}$ ) was added to $5 \mathrm{ml}$ of $10 \%$ aqueous $\mathrm{NaOH}$, and the mixture was heated at $70^{\circ} \mathrm{C}$ for $1 \mathrm{~h}$. The homogeneous solution was cooled to room temperature, diluted to $50 \mathrm{ml}$ with water, and then dialyzed for 5 days against running deionized water. The solution was concentrated to a few milliliters and finally freeze-dried to give a spongy polymer (IV). Yield, $33.9 \mathrm{mg}(98.3 \%)$. IR (KBr) 3400 (broad), 1600 (broad), and 1500 $\mathrm{cm}^{-1}$. The peaks in the NMR spectrum of IV in DMSO- $d_{6}$ were rather broad and overlapped with peaks due to the solvent and water, which made full assignment difficult. However, no peaks ascribable to amide $\mathrm{NH}$ and acetyl $\mathrm{CH}_{3}$ groups were found, indicating completion of the reaction.

\section{Poly(p-vinylphenyl 2-acetamido-2-deoxy- $\beta$-D- glucoside) (V) \\ Polymer III (100 mg) was dissolved in $10 \mathrm{ml}$} of pyridine by warming, and $10 \mathrm{ml}$ of acetic anhydride was added. After standing overnight at room temperature, the solution was poured into ice-cold water to precipitate the peracetylated polymer. It was collected on a glass filter, washed with water, and dried under vacuum. Yield, $106.6 \mathrm{mg}(96.6 \%)$.

The peracetylated polymer $(45 \mathrm{mg})$ was then dissolved in $10 \mathrm{ml}$ of dry methanol and $1 \mathrm{ml}$ of $0.1 \mathrm{~N} \mathrm{CH}_{3} \mathrm{ONa}$ in methanol was added. After standing for $3 \mathrm{~h}$ at room temperature, the selectively O-deacetylated polymer (V), precipitated as a white powder, was collected on a filter, washed with methanol, and dried in vacuo. Yield, $26.0 \mathrm{mg}(80.3 \%)$.

${ }^{1} \mathrm{H}$ NMR (DMSO- $\left.d_{6}\right) \delta 7.8(\mathrm{~s}, 1 \mathrm{H}$, amide -NHCO-), 6.1-7.2 (broad $\mathrm{m}, 4 \mathrm{H}$, aromatic $-\mathrm{CH}=)$, and $1.8\left(\mathrm{~s}, 3 \mathrm{H}\right.$, acetyl $\left.\mathrm{CH}_{3}-\right)$; the other peaks were difficult to assign owing to their broadness and overlapping with the solvent peaks. IR (KBr) 3400 (broad), 1640, 1550, and $1500 \mathrm{~cm}^{-1}$.

Inhibitory Activity of the Polymers for the Agglutination of Red Blood Cells by Lectins

An inhibition test was carried out in a $0.01 \mathrm{M}$ phosphate buffer solution ( $\mathrm{pH} 6.78$ for wheat germ agglutinin (WGA) and $\mathrm{pH} 6.83$ for potato lectin) containing $0.15 \mathrm{~mol} 1^{-1}$ of $\mathrm{NaCl}$, using a fresh human type A red blood cells suspension. The procedure was as follows. To $0.1 \mathrm{ml}$ of a phosphate buffer solution of a lectin (concentration, $1 \mathrm{mg} / 100 \mathrm{ml}$ ) were added $0.23 \mathrm{ml}$ of an aqueous solution containing a given amount of an inhibitor and $0.2 \mathrm{ml}$ of a red blood cells suspension. After a given period $(20 \mathrm{~min}$ for WGA and $1 \mathrm{~h}$ for potato lectin), the mixture was gently stirred to see if the cells were agglutinated or not. The minimum concentration of the inhibitor required to inhibit the agglutination was determined by double dilution steps.

\section{RESULTS AND DISCUSSION}

\section{Synthesis of Polymers}

Coupling of a glycosyl bromide and an alkoxide is one of the simplest ways to prepare some glycosides. In the reaction, hydroxyl groups of the glycosyl bromide should be protected by benzyl or other stable groups. Acetyl groups may be used in some cases; phenyl glycosides of 2,3,4,6-tetra- $O$-acetylglucose and 3,4,6-tri- $O$-acetylglucosamine ${ }^{15}$ were synthesized from acetylated glycosyl halides and sodium or potassium phenoxide. $p$-Vinylphenol was thus anticipated to afford a polymerizable free amino sugar derivative by reaction with acetylbromoglucosamine $\mathbf{I}$.

The monomer (II), $p$-vinylphenyl 3,4,6-tri$O$-acetyl-2-amino-2-deoxy- $\beta$-D-glucoside, was synthesized in a way similar to that for phenyl acetylated-aminoglucoside. ${ }^{15}$ The glycosidation of $\mathbf{I}$ with $p$-vinylphenol was attempted 
under various conditions, and the reaction with a theoretical amount of sodium on the basis of $\mathbf{I}$ and an excess of $p$-vinylphenol at room temperature resulted in the highest yield. Because of the instability of $p$-vinylphenol, the reaction mixture was kept below $20^{\circ} \mathrm{C}$ all through the procedures and should not be concentrated too much before removal of unreacted $p$-vinylphenol to avoid polymerization. II was obtained as colorless thin plates on recrystallization from ethanol. It was characterized by IR and NMR spectroscopies, specific rotation, and elemental analysis.

II was polymerized in a sealed tube in benzene with AIBN as the initiator at $60^{\circ} \mathrm{C}$ for $24 \mathrm{~h}$. The resulting viscous solution was diluted with methanol, and poured into ether to precipitate a white powdery polymer (III). The IR spectra of the polymers sometimes showed weak bands at 1640 and $1540 \mathrm{~cm}^{-1}$, characteristic of an amide. This indicates that some acetyl groups migrated from oxygen to nitrogen during polymerization. This migration could be avoided by carrying out the polymerization in thoroughly dried benzene distilled over sodium just before use.

The amount of the initiator affected the formation of III. As shown in Table I, the yield decreased and the viscosity increased with a decrease in initiator amount. With $0.4 \mathrm{~mol}^{\circ} \%$ AIBN, a polymer with high viscosity $(0.75 \mathrm{dl}$ $\mathrm{g}^{-1}$ ) was obtained. The polymers were soluble in dimethylacetamide (DMAc), dimethyl sulfoxide (DMSO), methanol, and pyridine, but became insoluble in benzene after isolation.

Deacetylation of polymer III was first attempted with an aqueous $1 \mathrm{~N}$ sodium hydrogencarbonate solution at $95^{\circ} \mathrm{C}$. The suspension of III became a homogeneous solution in $20 \mathrm{~min}$. After $2 \mathrm{~h}$, the solution was dialyzed against deionized water, and then freeze-dried. In the IR spectrum of the hydrolyzed polymer, there was no absorption of ester linkages. However, weak absorptions due to amide groups were observed, indicating $\mathrm{O} \rightarrow \mathrm{N}$ acetyl migration to have occurred to some extent
Table I. Polymerization of $p$-vinylphenyl 3,4,6tri- $O$-acetyl-2-amino-2-deoxy- $\beta$-D-glucoside ${ }^{\mathrm{a}}$

\begin{tabular}{|c|c|c|c|}
\hline \multirow{2}{*}{ No. } & AIMB concn & Yield & $\eta_{\text {inh }}{ }^{b}$ \\
\hline & $\mathrm{mol} \%$ & $\%$ & $\mathrm{dl} \mathrm{g}^{-1}$ \\
\hline 1 & 1.5 & 93.5 & 0.38 \\
\hline 2 & 1.0 & 84.4 & 0.45 \\
\hline 3 & 0.4 & 34.1 & 0.75 \\
\hline
\end{tabular}

a Monomer, $1 \mathrm{mmol}$; solvent, benzene $1.5 \mathrm{ml}$; time, $24 \mathrm{~h}$; temp, $60^{\circ} \mathrm{C}$.

b In DMAc, $c=0.25 \mathrm{~g} \mathrm{dl}^{-1}, 25^{\circ} \mathrm{C}$.

under the conditions used. The reaction was then carried out in a $10 \%$ sodium hydroxide solution at $70^{\circ} \mathrm{C}$ for $1 \mathrm{~h}$. After dialysis and freeze-drying, a white spongy material was obtained, whose IR and NMR spectra showed that acetyl groups were removed without any migration. The resulting polymer (IV) was soluble in water, and slightly soluble in DMAc and DMSO.

Polymer III was then converted to the polymer having $N$-acetylglucosamine units $(\mathbf{V})$ by $N$-acetylation with acetic anhydride in pyridine to give a fully acetylated derivative followed by selective $O$-deacetylation with sodium methoxide. An attempt of the reaction in $0.1 \mathrm{~N}$ sodium methoxide in methanol was unsuccessful owing to the occurrence of $\mathrm{N}$-deacetylation besides $O$-deacetylation, judging from the NMR spectrum. Selective $O$-deacetylation was achieved with $0.01 \mathrm{~N}$ sodium methoxide/methanol in $3 \mathrm{~h}$. A white powdery polymer $(\mathbf{V})$ was soluble in water, DMAc, and DMSO.

Figure 1 shows the IR spectra of these three polymers, III, IV, and V. In the spectrum of III, there is a strong absorption of ester linkages at $1730 \mathrm{~cm}^{-1}$. Two characteristic absorptions of amide groups are found at 1640 and $1540 \mathrm{~cm}^{-1}$ in the spectrum of $\mathbf{V}$.

\section{Interaction of the Polymers with Lectins}

Polymers IV and $\mathbf{V}$ have the constituting units of chitosan and chitin, respectively, and 


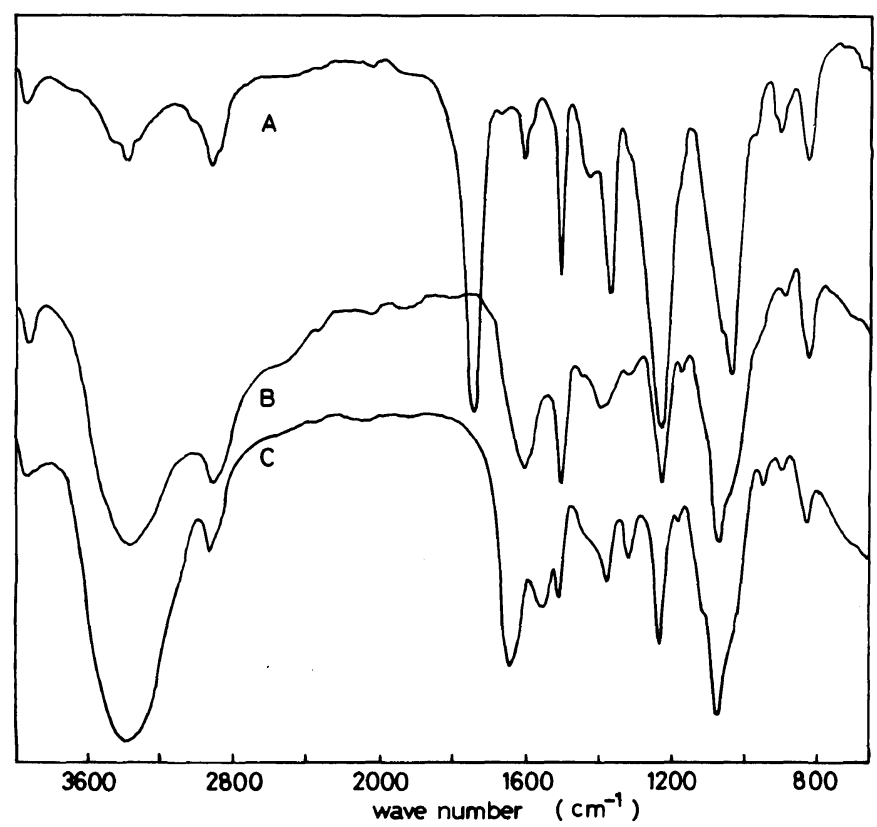

Figure 1. IR spectra of $\mathbf{A}$, poly( $p$-vinylphenyl 3,4,6-tri- $O$-acetyl-2-amino-2-deoxy- $\beta$-D-glucoside) (III); $\mathbf{B}$, poly $(p$-vinylphenyl 2-amino-2-deoxy- $\beta$-D-glucoside) (IV); C, poly( $p$-vinylphenyl 2-acetamido-2-deoxy- $\beta$-Dglucoside) (V).

are thus expected to show similar characteristic properties of these polysaccharides. As an example of the bioactivity of the polymers, the interaction with wheat germ agglutinin (WGA) and potato lectin was examined. These lectins have a specific affinity for polymers of $N$-acetylglucosamine linked in the $\beta-1,4$ fashion, and hence their agglutination activity toward red blood cells is clearly interfered with by the addition of water-soluble poly $(N$-acetylglucosamine)s. Moreover, the interference activity of the saccharides is reported to increase with the number of $\mathrm{N}$-acetylglucosamine units in the saccharides up to five. ${ }^{16}$ It is thus possible to evaluate the interaction of the polymers prepared here with the lectins by elucidating the minimum concentration of the polymers required for inhibition of agglutination.

An inhibition test was carried out in a phosphate buffer solution with type A red blood cells, using polymers IV and $\mathbf{V}$ and also some other water-soluble compounds containing $\mathrm{N}$-acetylglucosamine for comparison. The results are summarized in Table II. Minimum concentrations for inhibition were expressed as micromoles of pyranose units per milliliter. As shown in Table II, polymer $\mathbf{V}$ showed higher affinity for WGA than $N, N^{\prime}$-diacetylchitobiose and the same level of affinity as that of water-soluble chitin which is a partially deacetylated chitin with about $50 \%$ deacetylation. ${ }^{17}$ This indicates that WGA recognized polymer $\mathbf{V}$ as a chitin oligomer in the inhibition of the agglutination of red blood cells. Polymer IV, however, has no effect even at an almost saturated concentration, supporting the importance of the $\mathrm{N}$-acetyl groups.

Potato lectin, which has no affinity for monosaccharides, also interacted with polymer $\mathbf{V}$. However, the affinity is not so high as that of $N, N^{\prime}$-diacetylchitobiose, and lower than those of 6-O-(2-hydroxypropyl)chitin and water-soluble chitin. The difference in the af- 
Table II. Inhibitory activity of saccharides toward the agglutination of red blood cells by lectins ${ }^{\mathrm{a}}$

\begin{tabular}{|c|c|c|}
\hline \multirow{3}{*}{ Saccharide } & \multicolumn{2}{|c|}{ Minimum concentration for inhibition } \\
\hline & \multicolumn{2}{|c|}{$\mu \mathrm{mol}$ pyranose unit $/ \mathrm{ml}^{\mathrm{b}}$} \\
\hline & Wheat germ agglutinin & Potato lectin \\
\hline Polymer IV & $>64$ & $>64$ \\
\hline Polymer V & 0.25 & 32 \\
\hline$N$-Acetylglucosamine & 128 & $>512$ \\
\hline $\begin{array}{l}\text { Phenyl 2-acetamido-2- } \\
\text { deoxy- } \beta \text {-D-glucoside }\end{array}$ & 64 & $>64$ \\
\hline$N, N^{\prime}$-Diacetylchitobiose & 4 & 16 \\
\hline Water-soluble chitin & 0.25 & 0.25 \\
\hline 6-O-(2-Hydroxypropyl)chitin & 0.063 & 0.125 \\
\hline
\end{tabular}

a Fresh human type-A red blood cells were used.

b Each inhibitor was tested by serial double dilution steps.

finity of polymer $\mathbf{V}$ for the two lectins may probably be explained in terms of the difference in the affinity of the lectins for the monosaccharide, $N$-acetylglucosamine. WGA has an affinity for $N$-acetylglucosamine and seems to bind to the sugar units of polymer $\mathbf{V}$ as well as those on the surface of red blood cells. The neighboring sugar pendants would interact cooperatively with WGA to make the binding tight enough to suppress activities of WGA. Since potato lectin has no affinity for the monosaccharide and necessitates the $\beta-1,4$ oligomeric sequence for the interaction, only sequences of pendant $N$-acetylglucosamine groups of polymer $\mathbf{V}$ in appropriate conformations are effective, at least temporarily, to interact with the lectin. This would result in the weak interaction of polymer $\mathbf{V}$ and potato lectin.

The fact that the $N$-acetylglucosamine-containing polymer has a high affinity for lectins, comparable to that of oligosaccharides, seems to indicate the possibility of synthesizing polymers with bioactivities inherent in oligo- and polysaccharides in a simple manner.

Acknowledgment. The authors thank Maruzen Oil Co., Ltd. for providing $p$ - vinylphenol.

\section{REFERENCES}

1. K. Kobayashi and H. Sumitomo, Macromolecules, 13, 234 (1980).

2. S. Kimura and M. Imoto, Makromol. Chem., 50, 155 (1961).

3. L. A. Carpino, H. Ringsdorf, and H. Ritter, Makromol. Chem., 177, 1631 (1976).

4. M. Kawana and S. Emoto, Tetrahedron Lett., 4855 (1972)

5. W. A. P. Black, J. A. Colquhoun, and E. T. Dewar, Makromol. Chem., 122, 244 (1969).

6. K. Kurita, N. Hirakawa, and Y. Iwakura, Makromol. Chem., 180, 2331 (1979).

7. K. Kurita, K. Miyajima, T. Sannan, and Y. Iwakura, J. Polym. Sci., Polym. Chem. Ed., 18, 359 (1980).

8. K. Kurita, N. Hirakawa, H. Morinaga, and Y. Iwakura, Makromol. Chem., 180, 2769 (1979).

9. K. Kurita, N. Hirakawa, and Y. Iwakura, Makromol. Chem., 181, 1861 (1980).

10. B. Helferich and H.-J. Höffmann, Chem. Ber., 85, 175 (1952).

11. B. Helferich and K.-H. Jung, Z. Physiol. Chem., 311, 54 (1958)

12. K. Kobayashi, H. Sumitomo, and Y. Ina, Polym. J., 17, 567 (1985)

13. P. H. Gross, K. Brendel, and H. K. Zimmerman, Jr., Liebigs Ann. Chem., 683, 175 (1965).

14. K. Onodera and T. Komano, J. Org. Chem., 26, 3932 (1961).

15. C. G. Grieg, D. H. Leaback, and P. G. Walker, $J$. Chem. Soc., 879 (1961). 


\section{Polymers Having Pendant Amino Sugar Groups}

16. I. J. Goldstein and C. E. Hayes, "Advances in Cabohydrate Chemistry and Biochemistry," Vol. 35, 1978, p 127.
17. T. Sannan, K. Kurita, and Y. Iwakura, Makromol. Chem., 177, 3589 (1976). 